
портрета эритроцитов с учетом развития стрессовой реакции в условиях патологического процесса

\author{
Дерюгина А.В. • Иващенко М.Н.․ • Игнатьев П.С. ${ }^{3}$ Самоделкин А.Г. ${ }^{2}$
}

Актуальность. Современные методы клеточной диагностики востребованы при разработке новых подходов персонализированной медицины. К таким методам, активно внедряемым в диагностический процесс лечебных учреждений, можно отнести когерентную фазовую интерферометрию и клеточный микроэлектрофорез. Цель - обоснование возможности использования биофизических и морфоденситометрических показателей эритроцитов в качестве критериев эффективности терапии и развития адаптационных процессов у пациентов с гастроэнтерологическими заболеваниями. Материал и методы. Под наблюдением находились 25 больных в возрасте от 40 до 54 лет (11 мужчин и 14 женщин), из них 9 (36\%) - с язвенной болезнью желудка, 3 (12\%) с язвенной болезнью двенадцатиперстной кишки, 8 (32\%) - с острым гастритом, 5 (20\%) с острым панкреатитом. Биофизические и морфологические особенности эритроцитов периферической крови пациентов исследовали до и после проведения терапии с использованием методов клеточной диагностики - микроэлектрофореза и лазерной модуляционной интерференционной микроскопии. Параллельно оценивали динамику рутинных клинико-лабораторных показателей: количество эритроцитов и лейкоцитов, уровень гемоглобина, скорость оседания эритроцитов (СОЭ), лейкоцитарную формулу. Контрольную группу составили 10 здоровых доноров в возрасте от 36 до 52 лет. В экспериментах in vitro анализировали изменения электрофоретической подвижности эритроцитов (ЭФПЭ) и морфологии эритроцитов при действии адреналина и кортизола. Результаты. После проведения терапии у больных наблюдалось уменьшение содержания лейкоцитов (на 27\%), повышение моноцитов (в 2 раза) и снижение СОЭ (на 10\%) относительно показателей до лечения ( $p<0,05$ во всех случаях). ЭФПЭ увеличивалась на $12 \%$ $(1,37$ против 1,22 мкм $\times \mathrm{cm} / \mathrm{B} \times \mathrm{c}, \mathrm{p}<0,05)$. В эритроцитарной популяции обследованных пациентов до лечения по сравнению с контрольной группой отмечалось уменьшение доли дискоцитов $(85,2$ против 95,4\%, p <0,05), увеличение эхиноцитов, стоматоцитов и дегенеративно измененных форм (11, 2,8 и 1\% соответственно, $\mathrm{p}<0,05)$. После терапии содержание дискоцитов повышалось практически до физиологической нормы (91,3\%). Однако при этом поверхность клеток дискоидной формы оставалась неоднородной с наличием многочисленных микроспикул, что нашло отражение в изменении электрокинетических и морфологических свойств эритроцитов в ответ на развивающуюся в организме стресс-реакцию. Влияние стресс-реализующих систем подтверждено экспериментами in vitro по оценке воздействия адреналина $\left(1 \times 10^{-9} \mathrm{r} / \mathrm{мл}\right)$ и кортизола $\left(5 \times 10^{-7} \mathrm{r} / \mathrm{Mл}\right)$ на эритроциты. К 120-й минуте эксперимента под влиянием адреналина наблюдалось снижение ЭФПэ (1,14 против исходных 1,24 мкм × см/B×c, p <0,05) и увеличение сферичности клеток. При действии кортизола, напротив, ЭФПЭ увеличивалась $(1,72$ против 1,36 мкм $\times \mathrm{cm} / \mathrm{B} \times \mathrm{c}, \mathrm{p}<0,05)$, но выраженность эхиноцитарной трансформации была незначительной. Заключение. Биофизические и морфоденситометрические показатели эритроцитов, полученные с использованием современных экспресс-методов клеточного микроэлектрофореза и когерентной интерференционной микроскопии, объективно отражают интенсивность стресс-реакции при развитии патологического процесса и включение адаптационных механизмов в ходе проводимой терапии.

Ключевые слова: эритроциты, микроэлектрофорез, когерентная фазово-интерференционная микроскопия, гастроэнтерологические заболевания

Для цитирования: Дерюгина AB, Иващенко МН, Игнатьев ПС, Самоделкин АГ. Трансляционные исследования электрофоретической подвижности и фазового портрета эритроцитов с учетом развития стрессовой реакции в условиях патологического процесса. Альманах клинической медицины. 2018;46(8):765-71. doi: 10.18786/2072-0505-201846-8-765-771.

Поступила 22.02.2018;

принята к публикации 22.11.2018
$\mathrm{T}$ рансляционная медицина признана одним из актуальных направлений современной науки. Внедрение результатов фундаментальных исследований в практическое здравоохранение способствует переходу к персонализированной медицине, то есть позволяет врачу использовать возможности новых способов диагностики и оценки эффективности проводимого лечения $[1,2]$. К таким методам, активно внедряемым в диагностический процесс лечебных учреждений, можно отнести когерентную фазовую интерферометрию и клеточный микроэлектрофорез [3, 4].

Ранее нами установлено, что изменение электрофоретической подвижности эритроцитов (ЭФПЭ) позволяет характеризовать развитие 
стресс-реакции и включение адаптационных резервов организма $[5,6]$. Как показали эксперименты с моделированием стресса на животных, снижение ЭФПЭ наблюдается при активации симпато-адреналовой системы, тогда как рост ЭФПЭ связан с активацией гипофизарно-надпочечниковой системы и повышением резистентности организма [7]. Изучение ЭФПЭ при различных патологических состояниях выявило однонаправленную динамику данного показателя, проявляющуюся в его снижении относительно физиологической нормы, что может быть отражением разной степени выраженности стрессовой реакции [8-11]. Особенности ЭФПЭ определяются свойствами клеточных мембран, визуализация которых позволит, на наш взгляд, получить дополнительную информацию о перестройке поверхностных структур клеток в условиях нормы и патологии. Однако для верификации использования ЭФПЭ и параметров фазового портрета эритроцитов в качестве показателей патологического процесса необходимо сопоставить их изменения с результатами стандартных клинико-лабораторных исследований.

Цель работы - обоснование возможности использования биофизических и морфоденситометрических показателей эритроцитов в качестве критериев эффективности терапии и развития адаптационных процессов у пациентов с гастроэнтерологическими заболеваниями.

\section{Материал и методы}

Мы провели анализ показателей крови пациентов сгастроэнтерологическими заболеваниями (язвенная болезнь желудка и двенадцатиперстной кишки, острый гастрит, острый панкреатит). Группа пациентов набрана на основании результатов анкетирования, проводившегося перед госпитализацией на первичном приеме у врача-гастроэнтеролога на базе ГБУЗ НО Городская поликлиника № 50 Советского района г. Нижнего Новгорода. Критерием включения в исследование служило наличие у пациентов острого состояния, отсутствие ранее самостоятельно проводившегося лечения, а также добровольное согласие, полученное в соответствии с требованиями ст. 9 Федерального закона от 27.07.2006 «О персональных данных» № 152-Ф3. Исследования были одобрены локальным этическим комитетом Института биологии и биомедицины ФГАОУ ВО «Национальный исследовательский Нижегородский государственный университет им. Н.И. Лобачевского» (протокол № 47 от 11.09.2017).

Под наблюдением находились 25 больных в возрасте от 40 до 54 лет (11 мужчин
Дерюгина Анна Вячеславовна - д-р биол. наук, доцент, заведующая кафедрой физиологии и анатомии Института биологии и биомедицины ${ }^{1}$

Иващенко Марина Николаевна - канд. биол. наук, доцент кафедры физиологии и биохимии животных ${ }^{2}$ $\triangle$ 603107, г. Нижний Новгород, проспект Гагарина, 97, Российская Федерация. Тел.: +7 (831) 4626656. E-mail: mi11207 @rambler.ru

Игнатьев Павел Сергеевич - канд. физ.-мат. наук, главный конструктор ${ }^{3}$

\section{Самоделкин Александр}

Геннадьевич - д-р биол. наук, профессор, заведующий кафедрой физиологии и биохимии животных ${ }^{2}$

1 ФГАОУ ВО

«Национальный исследовательский Нижегородский государственный университет им. Н.И. Лобачевского»; 603950, г. Нижний Новгород, проспект Гагарина, 23, Российская Федерация

2 ФГБОУ вО

«Нижегородская государственная сельскохозяйственная академия»; 603107, г. Нижний Новгород, проспект Гагарина, 97, Российская Федерация

${ }^{3} \mathrm{AO}$ «Производственное объединение «Уральский оптикомеханический завод» им. Э.С. Яламова»; 620100 , г. Екатеринбург, ул. Восточная, 33 Б, Российская Федерация и 14 женщин), из них 9 (36\%) - с язвенной болезнью желудка, 3 (12\%) - с язвенной болезнью двенадцатиперстной кишки, 8 (32\%) - с острым гастритом, 5 (20\%) - с острым панкреатитом. Диагноз формулировался врачом в соответствии с общепринятыми клиническими стандартами на основании анамнеза и подтверждался лабораторными и клиническими исследованиями. Лечение пациентов включало проведение стандартных терапевтических мероприятий: медикаментозную терапию (полусинтетические пенициллины, холинолитики, антациды, блокаторы $\mathrm{H}_{2}$-гистаминовых рецепторов, цитопротекторы), физиотерапию, диету. Контрольную группу составили 10 здоровых доноров в возрасте от 36 до 52 лет.

Исследование ЭФПЭ, морфологии эритроцитов и клинический анализ крови проводили при поступлении пациентов в стационар до начала и после проведения терапевтических мероприятий перед выпиской. Для оценки ЭФПЭ готовили взвесь отмытых эритроцитов путем трехкратного центрифугирования при 1500 об/мин в течение 10 минут с 0,9\% раствором хлористого натрия. Суспензию клеток разводили в 10 мМ трис-HCl-буфере (pH $7,4)$ и измеряли ЭФПЭ методом микроэлектрофореза с использованием цитоферометра в нашей модификации [4], регистрируя время прохождения эритроцитами расстояния 100 мкм в трис-HCl-буфере с рН 7,4 при силе тока 12 мА. Величину ЭФПЭ определяли по формуле: $\mathrm{U}=\mathrm{S} / \mathrm{TH}$, где $\mathrm{S}$ - расстояние, на которое перемещались клетки, Т - время перемещения клеток на расстояние S, H - градиент потенциала. Величину градиента потенциала определяли по формуле: $\mathrm{H}=\mathrm{I}$ / gХ, где I - сила тока, g поперечное сечение камеры, $\chi$ - удельная электропроводимость среды [12].

Исследование комплексной фазометрии эритроцитов проведено методом лазерной модуляционной интерференционной микроскопии на микроскопе МИМ-340 (Екатеринбург, Россия). В работе использовали лазер с длиной волны 532 нм и объектив с увеличением $\times 20$, разрешение по поверхности до 15 нм, разрешение по вертикали - 0,1 нм, возможность контроля изделий с глубиной рельефа - до 600 нм $[13,14]$. Регистрировали морфологию нативных клеток без предварительной фиксации, что позволяло визуализировать модификацию клеток в режиме реального времени, изучать их морфологию и динамику внутриклеточных процессов. Исследование лабораторно-клинических показателей крови проводили стандартными клиническими методами [15].

В экспериментах in vitro используемые в опытах эритроциты трижды отмывали $0,9 \%$ раствором 
хлористого натрия и инкубировали с адреналином $\left(1 \times 10^{-9}\right.$ г/мл) и кортизолом $\left(5 \times 10^{-7} \mathrm{r} / \mathrm{мл}\right)$, регистрируя динамику изменения ЭФПЭ через 15 , $30,60,120$ минут от начала инкубации. Каждая серия включала по 20 опытов.

Для статистической обработки полученных данных использовали программу Biostat. Количественные переменные представляли в виде среднего арифметического значения и стандартной ошибки $(\mathrm{M} \pm \mathrm{m})$. Статистическую значимость полученных различий разности средних значений при соблюдении условий нормальности распределения и равенства дисперсий оценивали с применением t-критерия Стьюдента. В остальных случаях применялся критерий Манна - Уитни. Бинарные показатели оценивались с помощью точного критерия Фишера. За величину уровня статистической значимости различий принимали $\mathrm{p}<0,05$.

\section{Результаты и обсуждение}

Исследование клинико-лабораторных показателей крови и ЭФПЭ у обследованных больных выявило, что после проведенного лечения по сравнению с исходными данными отмечалось статистически значимое уменьшение количества лейкоцитов на $17 \%$, снижение скорости оседания эритроцитов (СОЭ) на $10 \%$, уменьшение количества лимфоцитов на $32 \%$ и увеличение моноцитов в 2 раза (табл. 1). Регистрация ЭФПЭ показала ее увеличение более чем на $12 \%$ относительно исходного уровня $(\mathrm{p}<0,05)$.

Восстановление клинико-лабораторных показателей до физиологической нормы является объективным свидетельством эффективности лечения патологического процесса. ЭФПЭ, сниженная при поступлении больных в стационар, после проведения терапии увеличивалась, превышая значения данного показателя в контрольной группе.

На величину электрофоретической подвижности клетки влияют многие факторы, в частности, физико-химические особенности мембраны и свойства окружающей клетку среды $[4,7]$. При прогрессировании патологических состояний изменяется микроокружение, $\mathrm{pH}$, состав и концентрация электролитов, что приводит к изменению величины поверхностного заряда циркулирующих эритроцитов. Снижение отрицательного заряда, а значит, и снижение ЭФПЭ отражает модификацию их мембранных свойств, ускорение агрегации, адгезии к эндотелию и изменение реологии крови пациента в условиях патологического процесса. Соответственно, при эффективной терапии происходит стабилизация структуры
Таблица 1. Изменение клинико-лабораторных показателей крови и электрофоретической подвижности эритроцитов у пациентов с гастроэнтерологическими заболеваниями

\begin{tabular}{llll}
\hline Показатель & Контроль & \multicolumn{2}{c}{$\begin{array}{c}\text { Пациенты с гастроэнтерологическими } \\
\text { заболеваниями }\end{array}$} \\
\cline { 3 - 4 } & & до лечения & после лечения \\
\hline Гемоглобин, г/л & $128,6 \pm 4,23$ & $114,7 \pm 4,77^{*}$ & $117,6 \pm 2,79$ \\
Эритроциты, ×10²/л & $4,5 \pm 0,24$ & $4,1 \pm 0,09^{*}$ & $4,16 \pm 0,13$ \\
СОЭ, мм/4 & $8,21 \pm 1,67$ & $18,19 \pm 1,45^{*}$ & $16,55 \pm 2,28^{*},+$ \\
Лейкоциты, ×10\%/л & $6,06 \pm 0,77$ & $8,46 \pm 0,92^{*}$ & $7,05 \pm 0,64^{\dagger}$ \\
Палочкоядерные, \% & $2,04 \pm 0,57$ & $1,14 \pm 0,47$ & $1,21 \pm 0,52$ \\
Сегментоядерные, \% & $58,01 \pm 3,05$ & $60,51 \pm 3,74$ & $57 \pm 3,35$ \\
Моноциты, \% & $18,14 \pm 2,55$ & $6,14 \pm 3,55^{*}$ & $12,36 \pm 2,59^{\dagger}$ \\
Лимфоциты, \% & $15,75 \pm 5,51$ & $32,21 \pm 5,56^{*}$ & $22,38 \pm 4,91^{\dagger}$ \\
ЭФПЭ, мкм×см/В×с & $1,3 \pm 0,02$ & $1,22 \pm 0,02^{*}$ & $1,37 \pm 0,03^{\dagger}$ \\
\hline
\end{tabular}

СОЭ - скорость оседания эритроцитов, ЭФПЭ - электрофоретическая подвижность эритроцитов Данные представлены в виде среднего арифметического значения и стандартной ошибки $(\mathrm{M} \pm \mathrm{m})$ * $\mathrm{p}<0,05$ по сравнению с показателями контрольной группы

${ }^{\dagger} \mathrm{p}<0,05$ по сравнению с показателями до лечения

Таблица 2. Морфологические типы фазово-интерференционных портретов эритроцитов

\begin{tabular}{|c|c|c|c|c|}
\hline \multirow[t]{2}{*}{ Группа } & \multicolumn{4}{|c|}{ Типы эритроцитов, \% } \\
\hline & дискоциты & эхиноциты & стоматоциты & $\begin{array}{c}\text { дегенеративно } \\
\text { измененные }\end{array}$ \\
\hline Контроль & $95,4 \pm 0,4$ & $3,8 \pm 0,7$ & $0,6 \pm 0,3$ & $0,2 \pm 0,1$ \\
\hline \multicolumn{5}{|c|}{ Пациенты с гастроэнтерологическими заболеваниями } \\
\hline до лечения & $85,2 \pm 0,5^{*}$ & $11 \pm 0,2^{*}$ & $2,8 \pm 0,7^{*}$ & $1 \pm 0,6$ \\
\hline после лечения & $91,3 \pm 0,3$ & $6 \pm 0,5$ & $2,1 \pm 0,7$ & $0,6 \pm 0,3$ \\
\hline
\end{tabular}

Данные представлены в виде среднего арифметического значения и стандартной ошибки $(\mathrm{M} \pm \mathrm{m})$ * $\mathrm{p}<0,05$ по сравнению с показателями контрольной группь

Таблица 3. Динамика изменения электрофоретической подвижности эритроцитов периферической крови после воздействия адреналином и кортизолом in vitro, $\mathrm{MKM} \times \mathrm{CM} / \mathrm{B} \times \mathrm{C}$

\begin{tabular}{llccc}
\hline Вид воздействия & \multicolumn{4}{l}{ Время после воздействия, минуты } \\
\cline { 2 - 5 } & 15 & 30 & 60 & 120 \\
\hline Адреналин & $1,24 \pm 0,05$ & $1,19 \pm 0,08^{*}$ & $1,15 \pm 0,07^{*}$ & $1,14 \pm 0,05^{*}$ \\
Кортизол & $1,36 \pm 0,03$ & $1,52 \pm 0,06^{*}$ & $1,96 \pm 0,06^{*}$ & $1,72 \pm 0,08^{*}$ \\
Физиологический раствор & $1,33 \pm 0,02$ & $1,36 \pm 0,06$ & $1,32 \pm 0,06$ & $1,35 \pm 0,04$ \\
\hline
\end{tabular}

Данные представлены в виде среднего арифметического значения и стандартной ошибки ( $\mathrm{M} \pm \mathrm{m})$ * $\mathrm{p}<0,05$ по сравнению с контрольными значениями (физиологический раствор) 
клеточной мембраны, восстановление активности ферментных и транспортных систем, повышение величины электрического заряда и восстановление ЭФПЭ до значений нормы.

Учитывая, что существенное влияние на ЭФПЭ оказывает поверхностная архитектоника белок-липидной структуры мембран [16], был проведен анализ морфоденситометрических показателей эритроцитов методом интерференционной микроскопии. У пациентов с гастроэнтерологической патологией доля измененных форм эритроцитов возрастала на 17\% по сравнению с группой контроля. Изменение формы эритроцитов в большей степени было связано с появлением эхиноцитов (табл. 2, рис. 1).

Не исключено, что увеличение количества эхиноцитов вызвано усилением окислительных процессов в клетках и появлением в них гемина [17]. При этом эритроциты с сохраненной формой дискоцита на различных участках клетки имели негладкую, неоднородную поверхность (см. рис. 1-2), что может быть обусловлено структурной перестройкой цитоскелета, конформационными изменениями и топографическим перераспределением молекул гемоглобина в сетчатой строме и подмембранных областях клетки [18] или начальной стадией перехода дискоцита в эхиноцит [19].

Проведение терапии способствовало снижению доли морфологически измененных форм эритроцитов и росту ЭФПЭ. Однако если фазовый профиль дискоцитов здоровых людей характеризовался близкой к равномерной ультраструктурой мембран и внутриклеточного содержимого (см. рис. 1А), то дискоциты больных, обследованных после курса терапии, имели негладкую поверхность с выростами (см. рис. 1Б). Появление неровностей на поверхности клеток может быть обусловлено начальной стадией перехода дискоцитов в эхиноциты, формирование которых сдерживается адаптационными процессами в клетке. Сходные изменения ультраструктуры мембран эритроцитов были зафиксированы при использовании опиатов [20]. У пациентов после лечения, несмотря на количественное восстановление дискоидных форм эритроцитов до нормальных значений, ультраструктура мембран также отличалась от контрольных образцов (см. рис. 1В). В этой клинической группе было зарегистрировано увеличение ЭФПЭ.

Имея в виду, что изменение ЭФПЭ отражает развитие стресс-реакции [8], рост показателя у гастроэнтерологических больных может указывать на уменьшение стрессовой реакции и развитие адаптационных процессов.

A
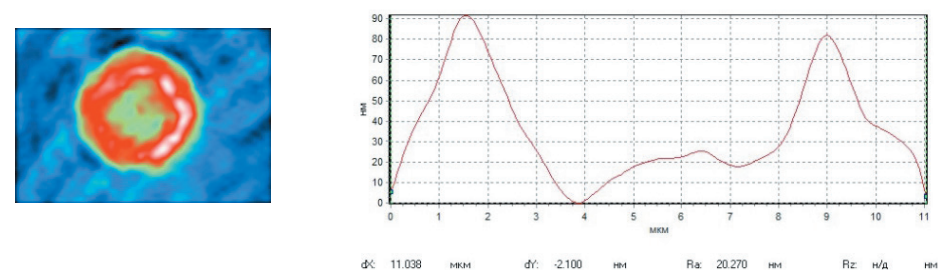

这
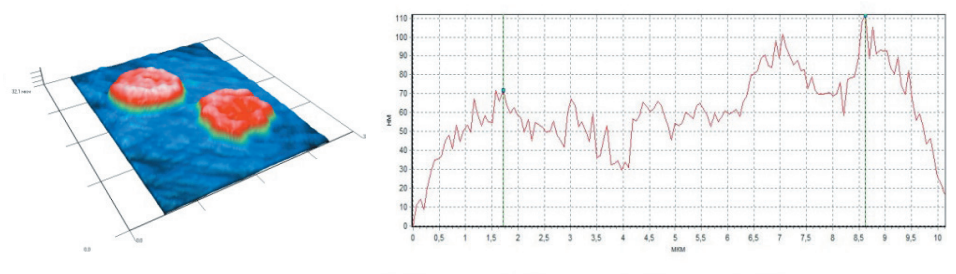

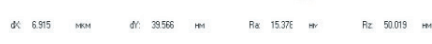

B
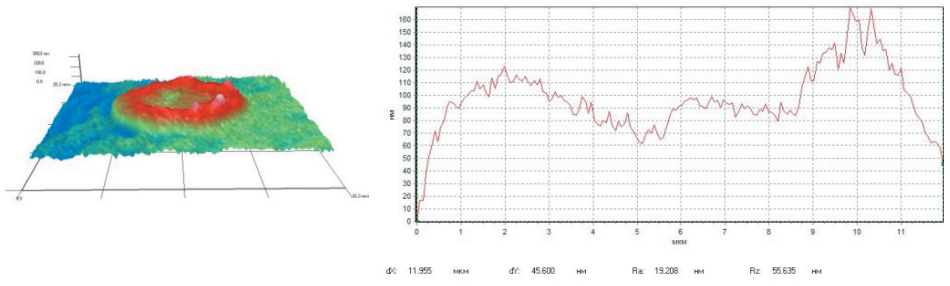

Рис. 1. Фазово-интерференционные портреты (слева) и фазовые профили (справа) эритроцитов периферической крови здоровых доноров (А), пациентов с гастроэнтерологическими заболеваниями до (Б) и после (В) курса терапии

A
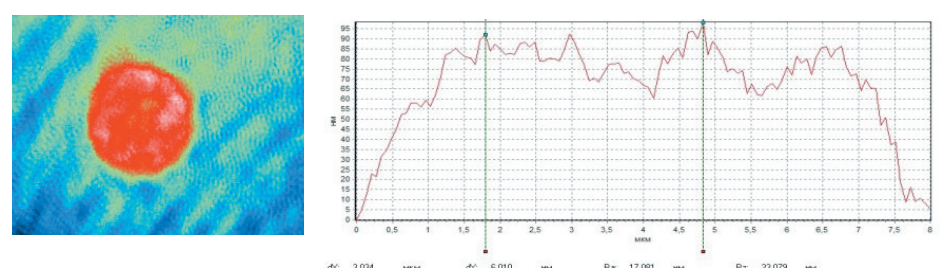

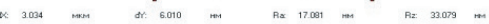

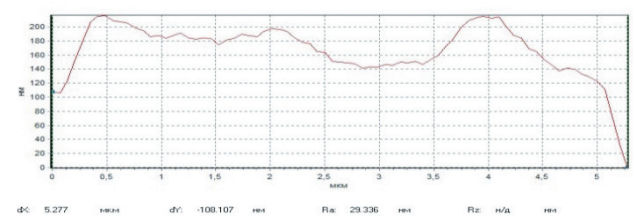

Рис. 2. Фазовый портрет (слева) и фазовый профиль (справа) эритроцитов in vitro при действии исследуемых веществ: адреналина (А) и кортизола (Б)

Для подтверждения данного положения нами были проведены эксперименты in vitro, связанные с анализом изменения ЭФПЭ и особенностей их фазово-интерференционных портретов при действии адреналина и кортизола, поскольку первая фаза стресс-реакции сопряжена с увеличением концентрации адреналина в периферической крови, тогда как вторая фаза стресса отражает развитие резистентности и сочетается с увеличением 
концентрации кортизола, действие которого направлено на элиминацию стресса.

Исследование показало, что адреналин, начиная с 30 минут наблюдения, вызывал однонаправленное снижение ЭФПЭ, в то время как под действием кортизола, напротив, отмечено прогрессирующее увеличение этого показателя (табл. 3). Зарегистрированы особенности изменения морфологии эритроцитов в условиях эксперимента: адреналин вызывал увеличение сферичности клеток, а при действии кортизола наблюдалось появление эхиноцитов, однако выраженность эхиноцитарной трансформации была незначительной (рис. 2).

Таким образом, можно предположить, что при развитии патологического процесса в зависимости от его интенсивности возникает стрессовая реакция, которая проявляется в изменении морфологии эритроцитов и их электрофоретической подвижности. Чем интенсивнее идет развитие стресса, тем больше патологически измененных эритроцитов с эхиноцитарной трансформацией и тем ниже ЭФПЭ. Данный процесс может быть связан с эффектом адреналина, который при взаимодействии с рецепторами эритроцитов вызывает активацию фосфолипаз, усиливает процесс липопероксидации, что модифицирует морфофункциональную организацию клеток и увеличивает проницаемость мембран [21]. Проведение терапевтических мероприятий ограничивает стресс-реакцию, которая может быть обусловлена включением

\section{Конфликт интересов \\ Авторы декларируют от- сутствие явных и потен- циальных конфликтов интересов, связанных с публикацией настоя- щей статьи. \\ Финансирование \\ Исследование выпол- нено при финансовой поддержке РФФИ в рам- ках научного проекта № 18-016-00195.}

адаптационных процессов в организме, что отражается на структуре эритроцитов: уменьшение эхиноцитарной трансформации в сочетании с повышенным уровнем ЭФПЭ. Данные процессы, вероятно, могут быть обусловлены действием кортизола. Глюкокортикоиды играют важную роль в регуляции связанного со стрессом гомеостаза (центральной нервной системы, сердечно-сосудистой системы, обмена веществ и иммуновоспалительной реакции). Кортизолу принадлежит ключевая роль в обеспечении гомеостаза всего гипоталамо-гипофизарно-кортикоидного комплекca, ответственного за развитие неспецифических механизмов реактивности организма [22].

\section{Заключение}

Показатели ЭФПЭ и денситометрические параметры живых эритроцитов, полученные с использованием методов клеточного электрофореза и лазерной интерференционной микроскопии, объективно отражают особенности изменения морфофункционального состояния клеток при развитии патологического процесса. Данные методы могут быть использованы для количественной характеристики степени стрессовой реакции и развития адаптационных процессов, что особенно важно при переходе к персонализированной медицине, поскольку уровень адаптационных резервов организма индивидуален и должен учитываться при разработке конкретной терапевтической стратегии. (ङ)

\section{Литература}

1. Пальцев МА, Белушкина НН. Трансляционная медицина - новый этап развития молекулярной медицины. Молекулярная медицина. 2012;(4):3-6.

2. Колбин АС, Гапешин РА, Малышев СМ. Современные подходы к организации трансляционных исследований. Педиатрическая фармакология. 2014;11(3):15-9. doi: 10.15690/pf.v11i3.1002.

3. Popescu G, Park Y. Quantitative phase imaging in biomedicine. J Biomed Opt. 2015;20(11): 111201. doi: 10.1117/1.JBO.20.11.111201.

4. Федин АИ, Василенко ИА, Бадалян КР. Влияние холестерина на электрокинетические свойства мембран эритроцитов при хронической ишемии головного мозга. Журнал неврологии и психиатрии им. С.С. Корсакова. 2015;115(9-2):30-7.

5. Antipenko EA, Deryugina AV, Gustov AV. Effects of nonspecific cytoprotective treatment on stress resistance and compensatory potential in patients with chronic cerebral ischemia. Neurosci Behav Physi. 2017;47(7):817-20. doi: 10.1007/s11055-017-0474-3.
6.Бояринов ГА, Дерюгина АВ, Яковлева ЕИ, Зайцев РP, Шумилова АВ, Бугрова МЛ, Бояринова ЛВ, Филиппенко ЕС, Соловьева ОД. Фармакологическая коррекция микроциркуляции у крыс, перенесших черепно-мозговую травму. Цитология. 2016;58(8):610-7.

7. Крылов ВН, Дерюгина АВ, Плескова СН. Электрофоретическая подвижность и морфометрия эритроцитов крыс при стрессовых воздействиях. Современные технологии в медицине. 2010;(4):23-6.

8. Стародумов ВЛ, Калинина НГ, Горбунов ВА. Состояние мембран эритроцитов как индикатор воздействия свинца окружающей среды. Вестник Ивановской медицинской академии. 2013;18(4):16-9.

9. Сашенков СЛ, Алачева ЛВ. Оценка реактивности периферического отдела эритрона у детей с воспалительными заболеваниями органов дыхания. Вестник Тюменского государственного университета. Экология и природопользование. 2014;(6):123-31.

10. Veshapidze N, Chigogidze T, Managadze L, Gabunia N, Kotrikadze N. Dynamics of the struc- tural and electrical characteristics of erythrocytes in men with metastatic adenocarcinoma of the prostate before and after plastic orchiectomy. Georgian Med News. 2007;(153):11-4.

11.Дерюгина AB, Шумилова AB, Филиппенко ЕС, Галкина ЯВ, Симутис ИС, Бояринов ГА. Функционально-биохимические показатели эритроцитов при использовании мексикора в посттравматический период экспериментальной кровопотери и сочетанной черепно-мозговой травмы у крыс. Бюллетень экспериментальной биологии и медицины. 2017;164(7):34-7.

12. Дерюгина АВ, Бояринов ГА, Симутис ИС, Никольский ВО, Кузнецов АБ, Ефимова ТС. Коррекция озонированной эритроцитной массой метаболических показателей эритроцитов и структуры миокарда после острой кровопотери. Цитология. 2018;60(2): 89-95. doi: 10.31116/tsitol.2018.02.03.

13. Атаходжаев И, Игнатьев П, Индукаев К, Осипов П. Лазерная интерференционная микроскопия для нанотехнологий. Фотоника. 2012;32(2):52-5. 
14. Василенко ИА, Кардашова 33, Тычинский ВП, Вишенская ТВ, Лифенко РА, Валов АЛ, Иванюта ИВ, Агаджанян БЯ. Клеточная диагностика: возможности витальной компьютерной микроскопии. Вестник последипломного медицинского образования. 2009;(3-4):64-8.

15. Меньшиков ВВ, Долгов ВВ, ред. Клиническая лабораторная диагностика. Национальное руководство. В 2 томах. Том 1. М.: ГЭОТАР-Медиа; 2012. 928 с.

16. Cook GM. Glycobiology of the cell surface: Its debt to cell electrophoresis 1940-65. Electrophoresis. 2016;37(11):1399-406. doi: 10.1002/elps.201500476.

17.Сергунова ВА, Черняев АП, Козлов АП, Близнюк УА, Борщеговская ПЮ, Козлова ЕК, Черныш АМ. Наноструктура мембран эритроцитов при интоксикации крови. Ис-

\section{References}

1. Paltsev MA, Belushkina NN. Translational medicine - a new stage of molecular medicine development. Molecular Medicine. 2012;(4):3-6. Russian.

2. Kolbin AS, Gapeshin RA, Malyshev SM. Modern approaches to the organization of translational research. Pediatric Pharmacology. 2014;11(3): 15-9. Russian. doi: 10.15690/pf.v11i3.1002.

3. Popescu G, Park Y. Quantitative phase imaging in biomedicine. J Biomed Opt. 2015;20(11): 111201. doi: 10.1117/1.JBO.20.11.111201.

4. Fedin AI, Vasilenko IA, Badalyan KR. The effect of cholesterol on the electrokinetic properties of erythrocyte membranes in chronic cerebral ischemia. Zhurnal Nevrologii i Psihiatrii imeni S.S. Korsakova. 2015;115(Special Issue 9):30-7. Russian.

5. Antipenko EA, Deryugina AV, Gustov AV. Effects of nonspecific cytoprotective treatment on stress resistance and compensatory potential in patients with chronic cerebral ischemia. Neurosci Behav Physi. 2017;47(7):817-20. doi: 10.1007/s11055-017-0474-3.

6. Bojarinov GA, Deryugina AV, Jakovleva El, Zajcev RR, Shumilova AV, Bugrova ML, Bojarinova LV, Filippenko ES, Solov'eva OD. Pharmacological correction of microcirculation in rats suffered a traumatic brain injury. Tsitologiya. 2016;58(8):610-7. Russian.

7. Krylov VN, Deryugina AV, Pleskova SN. Electrophoretic mobility and morphometry of the rat erythrocytes at the stress effects. Sovremennye Tehnologii v Medicine. 2010;(4):23-6. Russian.

8. Starodumov VL, Kalinina NG, Gorbunov VA. Status of erythrocyte membranes as an indicator of environmental lead exposure abstract. Bulletin of the Ivanovo Medical Academy. 2013;18(4):16-9. Russian.

9. Sashenkov SL, Alacheva LV. Reactivity of peripheral erythron children with inflammatory следование с помощью атомной силовой микроскопии. Альманах клинической медицины. 2016;44(2):234-41. doi: 10.18786/20720505-2016-44-2-234-241.

18. Rodnenkov OV, Luneva OG, Ulyanova NA, Maksimov GV, Rubin AB, Orlov SN, Chazov El. Erythrocyte membrane fluidity and haemoglobin haemoporphyrin conformation: features revealed in patients with heart failure. Pathophysiology. 2005;11(4):209-13. doi: 10.1016/j. pathophys.2004.12.001.

19.Браже АР, Браже НА, Сосновцева ОВ, Павлов АН, Мозекильде Э, Максимов ГВ. Исследование клеточной динамики с помощью интерференционной микроскопии с применением вейвлет-анализа. Компьютерные исследования и моделирование. 2009;1(1):77-83.

20. Moroz VV, Chernysh AM, Kozlova EK, Borshegovskaya PY, Bliznjuk UA, Rysaeva RM, Gudko-

respiratory system. Tyumen State University Herald. Natural Resource Use and Ecology. 2014;(6):123-31. Russian.

10. Veshapidze N, Chigogidze T, Managadze L, Gabunia N, Kotrikadze N. Dynamics of the structural and electrical characteristics of erythrocytes in men with metastatic adenocarcinoma of the prostate before and after plastic orchiectomy. Georgian Med News. 2007;(153): 11-4.

11. Deryugina AV, Shumilova AV, Filippenko ES, Galkina YV, Simutis IS, Boyarinov GA. Functional and biochemical parameters of erythrocytes during mexicor treatment in posttraumatic period after experimental blood loss and combined traumatic brain injury. Bull Exp Biol Med. 2017;164(1):26-9. doi: 10.1007/s10517-0173918-4.

12. Deryugina AV, Boyarinov GA, Simutis IS, Nikolskiy VO, Kuznetsov AB, Efimova TS. Correction of metabolic indicators of erythrocytes and the structure of myocardium after acute blood loss using an ozonized erythrocytal mass. Tsitologiya. 2018;60(2):89-95. Russian. doi: 10.31116/tsitol.2018.02.03.

13. Atokhodjaev A, Ignatyev I, Indukaev K, Osipov P. Laser interferometric microscopy for nanotechnologies. Photonics. 2012;32(2): 52-5. Russian.

14. Vasilenko IA, Kardashova ZZ, Tychinskiy VP, Vishenskaya TV, Lifenko RA, Valov AL, Ivanyuta IV, Agadzhanyan BYa. Cellular diagnostics: the possibilities of vital computer microscopy. Journal of Postgraduate Medical Education. 2009;(3-4):64-8. Russian.

15. Men'shikov VV, Dolgov VV, editors. Clinical laboratory diagnostics. National guidelines. In 2 vol. Vol. 1. Moscow: GEOTAR-Media; 2012. 928 p. Russian.

16. Cook GM. Glycobiology of the cell surface: Its debt to cell electrophoresis 1940-65. va OY. Comparison of red blood cell membrane microstructure after different physicochemical influences: atomic force microscope research. J Crit Care. 2010;25(3):539.e1-12. doi: 10.1016/j.jcrc.2010.02.007.

21. Макшанова ГП, Устьянцева ИМ, Петухова ОВ, Агаджанян ВВ. Изменение проницаемости эритроцитарных мембран и показателей липидного обмена у больных с политравмой при раннем и отсроченном оперативном лечении. Физиология человека. 2003;29(1):95-9.

22. Калий ВВ. Состояние синтеза и метаболизма глюкокортикоидных гормонов у больных раком гортани молодого возраста. Сибирский медицинский журнал (Томск). 2010;25(1):15-6.

Electrophoresis. 2016;37(11):1399-406. doi: 10.1002/elps.201500476.

17. Sergunova VA, Chernyaev AP, Kozlov AP, Bliznyuk UA, Borshchegovskaya PY, Kozlova EK, Chernysh AM. The nanostructure of erythrocyte membranes under blood intoxication: an atomic force microscopy study. Almanac of Clinical Medicine. 2016;44(2):234-41. Russian. doi: 10.18786/2072-0505-2016-44-2-234-241.

18. Rodnenkov OV, Luneva OG, Ulyanova NA, Maksimov GV, Rubin AB, Orlov SN, Chazov El. Erythrocyte membrane fluidity and haemoglobin haemoporphyrin conformation: features revealed in patients with heart failure. Pathophysiology. 2005;11(4):209-13. doi: 10.1016/j. pathophys.2004.12.001

19. Brazhe AR, Brazhe NA, Sosnovtseva OV, Pavlov AN, Mosekilde E, Maksimov GV. Wavelet-based analysis of cell dynamics measured by interference microscopy. Computer Research and Modeling. 2009;1(1):77-83. Russian.

20. Moroz VV, Chernysh AM, Kozlova EK, Borshegovskaya PY, Bliznjuk UA, Rysaeva RM, Gudkova OY. Comparison of red blood cell membrane microstructure after different physicochemical influences: atomic force microscope research. J Crit Care. 2010;25(3):539.e1-12. doi: 10.1016/j.jcrc.2010.02.007.

21. Makshanova GP, Ust'yantseva IM, Petukhova OV, Agadzhanyan VV. Changes in the permeability of erythrocyte membranes and lipid metabolism in patients with polytrauma in early and delayed surgical treatment. Human Physiology. 2003;29(1):95-9. Russian.

22. Kalyi VV. Synthesis and metabolism of glucocorticoid hormones in patients of young age groups having laryngeal cancer. Siberian Medical Journal. 2010;25(1):15-6. Russian. 


\title{
Translational studies of electrophoretic mobility and phase picture of erythrocytes with consideration of development of stress response during a pathological process
}

\author{
A.V. Deryugina' • M.N. Ivashchenko² • P.S. Ignat'ev • \\ A.G. Samodelkin ${ }^{2}$
}

Rationale: Modern cell diagnostic methods are in high demand during the development of new approaches in personalized medicine. Coherent phase interferometry and cell microelectrophoresis are among such methods that are being actively introduced into the diagnostic process in medical institutions. Aim: To substantiate the potential use of biophysical and morphodensitometrical erythrocytes parameters as criteria of treatment efficacy and course of adaptation process in patients with gastrointestinal tract disorders. Materials and methods: The study included 25 patients aged from 40 to 54 years (11 males and 14 females), among them 9 (36\%) with gastric peptic ulcer, $3(12 \%)$ with duodenal ulcer, 8 (32\%) with acute gastritis, and $5(20 \%)$ with acute pancreatitis. Biophysical and morphological particulars of peripheral blood erythrocytes were assessed before and after treatment using cell diagnostic techniques, such as microelectrophoresis and laser modulation interference microscopy. Also, we evaluated changes over time in routine clinical laboratory tests, such as red and white blood cell counts, hemoglobin levels, and erythrocyte sedimentation rate (ESR), and differential leukocyte counts. The control group included 10 healthy donors aged from 36 to 52 years. In vitro experiments were performed to assess the erythrocyte electrophoretic mobility (EEPM) and morphology of erythrocytes treated with epinephrine or cortisol. Results: After the treatment, the patients demonstrated a decrease in their leukocyte counts (by 27\%), a 2-fold increase in monocyte counts and an ESR decrease (by 10\%), compared to the corresponding baseline values before treatment $(p<0.05$ for all comparisons). EEPM increased by $12 \%$ ( 1.37 vs. $1.22 \mathrm{mcm} \times \mathrm{cm} / \mathrm{V} \times \mathrm{s}, \mathrm{p}<0.05)$. The erythrocyte pool of the patients before treatment, had a decreased proportion of discocytes, compared to that in the control group ( 85.2 vs. $95.4 \%, p<0.05$ ), increased proportions of echinocytes, stomatocytes and degenerative forms (11, 2.8 and $1 \%$, respectively, $\mathrm{p}<0.05$ ). After the treatment, the discocytes counts increased virtually up to their physiological normal range (91.3\%). However, the surface of the discoid cells remained heterogeneous with multiple microspicules; this resulted in changes of electrokinetic and morphological properties of erythrocyte response to stress reaction occurring in the body. The impact of the stress effectors was confirmed in in vitro experiments assessing the effects of epinephrine $\left(1 \times 10^{-9} \mathrm{~g} / \mathrm{mL}\right)$ and cortisol $\left(5 \times 10^{-7} \mathrm{~g} / \mathrm{mL}\right)$ on erythrocytes. At 120 minutes of the experiment, epinephrine decreased EEPM (1.14 vs. $1.24 \mathrm{mcm} \times \mathrm{cm} / \mathrm{V} \times \mathrm{s}$ at baseline, $\mathrm{p}<0.05$ ) and increased cell sphericity. On the contrary, cortisol increased EEPM (1.72 vs. $1.36 \mathrm{mcm} \times \mathrm{cm} / \mathrm{V} \times \mathrm{s}, \mathrm{p}<0.05$ ), with non-significant echinocytic transformation. Conclusion: Biophysical and morphodensitometric parameters of red blood cells obtained with the use of current express methods of cell microelectrophoresis and coherent interference microscopy help to objectivize the intensity of stress response during a pathological process and activation of adaptation mechanisms during the treatment.

Key words: erythrocytes, microelectrophoresis, coherent phase interference microscopy, gastrointestinal tract disorders

For citation: Deryugina $A V$, Ivashchenko MN, Ignat'ev PS, Samodelkin AG. Translational studies of electrophoretic mobility and phase picture of erythrocytes with consideration of development of stress response during a pathological process. Almanac of Clinical Medicine. 2018;46(8):765-71. doi: 10.18786/2072-0505-2018-46-8-765-771.

Received 22 February 2018;

accepted 22 November 2018

\section{Conflict of interests}

The authors declare that they have no conflicts of interest.

Anna V. Deryugina - ScD in Biology, Head of the Chair of Physiology and Anatomy, Institute of Biology and Biomedicine

Marina N. Ivashchenko - PhD in Biology, Associate Professor, Chair of Physiology and Biochemistry of Animals ${ }^{2}$

$\triangle 97$ Prospekt Gagarina, Nizhny Novgorod, 603107, Russian Federation. Tel.: +7 (831) 4626656 E-mail:mi11207@rambler.ru

Pavel S. Ignat'ev - PhD in Physics and Mathematics, Chief Designer ${ }^{3}$

Aleksandr G. Samodelkin - ScD in Biology, Professor, Head of the Chair of Physiology and Biochemistry of Animals ${ }^{2}$
Lobachevsky State University of Nizhny Novgorod 23 Prospekt Gagarina, Nizhny Novgorod, 603950, Russian Federation

${ }^{2}$ Nizhny Novgorod State Agricultural Academy; 97 Prospekt Gagarina, Nizhny Novgorod, 603107 Russian Federation

3JSC "Production Association "Ural Optical and Mechanical Plant named after Mr. E.S. Yalamov" (UOMZ); 33 B Vostochnaya ul., Ekaterinburg, 620100 , Russian Federation 